\title{
Short-pulse, extreme-ultraviolet continuum emission from a table-top laser plasma light source
}

\author{
O. Meighan, A. Gray, J.-P. Mosnier, W. Whitty, and J. T. Costello ${ }^{\text {a) }}$ \\ School of Physical Sciences, Dublin City University, Dublin 9, Ireland \\ C. L. S. Lewis and A. MacPhee \\ Queens University of Belfast, Belfast BT7 1NN, Northern Ireland \\ R. Allott, I. C. E. Turcu, and A. Lamb \\ Rutherford Appleton Laboratory, Chilton, Didcot OX11 OQX, United Kingdom
}

(Received 30 September 1996; accepted for publication 20 January 1997)

\begin{abstract}
We have observed extreme-ultraviolet (XUV) "line-free" continuum emission from laser plasmas of high atomic number elements using targets irradiated with $248 \mathrm{~nm}$ laser pulses of 7 ps duration at a power density of $\sim 10^{13} \mathrm{~W} / \mathrm{cm}^{2}$. Using both dispersive spectroscopy and streak camera detection, the spectral and temporal evolution of XUV continuum emission for several target atomic numbers has been measured on a time scale with an upper limit of several hundred picoseconds limited by amplified spontaneous emission. (C) 1997 American Institute of Physics.
\end{abstract}

[S0003-6951(97)02212-2]

The advent of table-top lasers capable of generating picosecond/subpicosecond pulses with energies in the range of $\mathrm{mJs}$ to hundreds of mJs has permitted the study of lasertarget interactions at ultrahigh irradiances (up to $10^{18}$ W/ $\mathrm{cm}^{2}$ ). Stimulated Raman backscatter, ${ }^{1}$ hard $\mathrm{x}$ rays with energies up to $1 \mathrm{MeV},{ }^{2}$ high harmonics of the laser frequency, ${ }^{3}$ subpicosecond FIR emission, ${ }^{4}$ and $\mathrm{MeV}$ electrons produced by laser wake-field acceleration ${ }^{5}$ have all been observed from such plasmas. Most experiments have observed incoherent $\mathrm{x}$-ray emission ${ }^{6-16}$ at photon energy $h \nu>1 \mathrm{KeV}$, where $\mathrm{x}$-ray pulse durations were measured, they were predominantly on the picosecond time scale.

Plasmas formed by table-top long pulse length (10-100 ns) lasers generating pulses of moderate energy (10s-100s $\mathrm{mJ}$ ) have become well established light sources in many laboratories. For typical on target irradiances of $10^{12}$ $\mathrm{W} / \mathrm{cm}^{2}$, such plasmas are brightest at sub-KeV photon energies. Extreme ultraviolet (XUV) emission durations are comparable with the laser pulse width ${ }^{17}$ and increase to typically hundreds of nanoseconds with decreasing photon energy into the vacuum ultraviolet (VUV). ${ }^{18}$

The observation of clean line-free continuum emission from such plasmas formed on high $Z$ targets (e.g., rare earths) by Carroll and co-workers ${ }^{19}$ opened up the possibility of a high brightness, table-top continuum light source for photoabsorption applications which had been exclusively limited to synchrotron light sources. To date, long pulse laser plasma continua have been used as secondary VUV light source standards, ${ }^{20}$ for photoelectron spectroscopy, ${ }^{21}$ soft $\mathrm{x}$-ray lithography, ${ }^{22}$ VUV reflectivity measurements ${ }^{23}$ nearedge x-ray absorption spectroscopy (NEXAFS) ${ }^{24}$ pulsed laser deposition dynamics, ${ }^{25}$ and XUV/VUV photoabsorption of laser produced plasmas. ${ }^{26,27}$

An important postscript in laser plasma continua development is an experiment using the Nd:Glass Vulcan laser at the EPSRC Central Laser Facility ${ }^{28}$ which demonstrated that XUV continua with subnanosecond pulse durations were

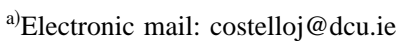

possible. Measurements of a thulium plasma spectrum driven by a $2 \omega(0.53 \mu \mathrm{m}) 80 \mathrm{ps}$ amplified spontaneous emission (ASE) free laser pulse with an on-target irradiance of $\sim 10^{15} \mathrm{~W} / \mathrm{cm}^{2}$ showed continuum emission over the wavelength range of 3-30 nm on a time scale of $\sim 100 \mathrm{ps}$.

A table-top, high average power laser plasma x-ray source $^{29}$ was developed at RAL using a picosecond excimer laser system. This system demonstrated very high (11\%) conversion efficiency from laser energy to $1 \mathrm{~nm}(\mathrm{Cu} L$ shell) $\mathrm{x}$-ray radiation by using a very high laser power density $\left(\sim 10^{15} \mathrm{~W} / \mathrm{cm}^{2}\right)$ on target. This letter investigates the suitability of this system, used at moderate on-target irradiance, to generate subnanosecond "line-free" XUV continuum emission from high atomic number plasmas. Time integrated dispersive spectroscopy was used to record the XUV continuum emission as a function of target atomic number. The "spectral purity," single shot sensitivity and an upper time limit on the duration of broad band XUV emission were established in order to determine the suitability of the source for potential applications in, e.g., "pump and probe" type studies.

A schematic diagram of the experimental setup used to measure time integrated spectra is shown in Fig. 1. A Spectra Physics-375 synchronously pumped mode locked dye laser operating at $82 \mathrm{MHz}$ produced a series of $746 \mathrm{~nm} 7 \mathrm{ps}$ pulses

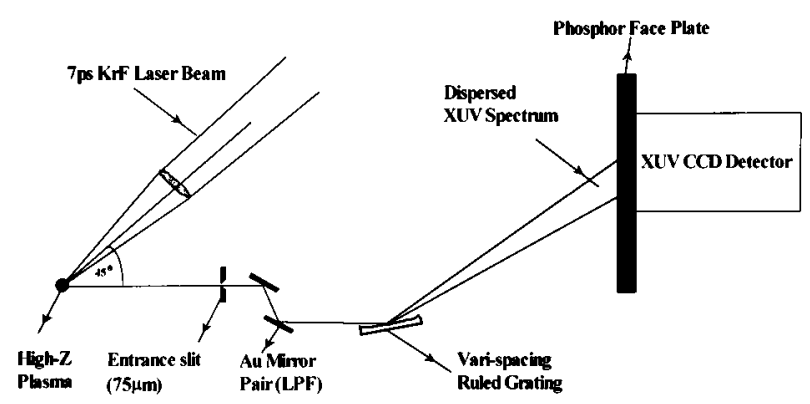

FIG. 1. Experimental setup used to record time integrated XUV spectra. For time resolved measurements, the grating and XUV multichannel detector were replaced by a thin film filter and XUV sensitive streak camera, respectively. 
separated by $12 \mathrm{~ns}$ which were then converted to the third harmonic at $248 \mathrm{~nm}$ and amplified in single pass in a pair of $\mathrm{KrF}$ excimer lasers. ${ }^{29}$ A $20 \mathrm{~ns}$ pump cycle in the two excimer lasers resulted in two 7 ps pulses, each having an average energy of $15 \mathrm{~mJ}$, within each $\mathrm{KrF}$ laser cycle. A $1 \mathrm{~m} f / 10$ plano convex lens was used to focus laser light to an irradiance of $\sim 10^{13} \mathrm{~W} / \mathrm{cm}^{2}$ onto both continuously moving tape and rotating cylindrical targets in vасио. Spectra were recorded using a flat field spectrometer (FFS) similar to that discussed by Kita and co-workers ${ }^{30}$ operated in either of two modes: for moderate resolution, an entrance slit (width $=75$ $\mu \mathrm{m})$ was located $\sim 230 \mathrm{~nm}$ from the grating center while for high throughput with lower resolution a slitless mode was employed with a source-grating distance of $\sim 900 \mathrm{~mm}$. The dispersed XUV spectrum fell on a phosphor coated faceplate and the resulting visible image was read out by a synchronized and fiber-optically coupled CCD camera system. The 1024 pixel length of the CCD covered a photon energy range of approximately $60-240 \mathrm{eV}$ with dispersion across the detector array varying from $\sim 0.06 \mathrm{eV}$ per pixel at $60 \mathrm{eV}$ to $\sim 0.5 \mathrm{eV}$ per pixel at $240 \mathrm{eV}$. Studies were confined to the $\mathrm{XUV} /$ soft $\mathrm{x}$-ray region from 70 to $300 \mathrm{eV}$. High order spectral contributions from plasma light of photon energy $>300$ $\mathrm{eV}$ were almost eliminated by using a double reflection from a pair of gold mirrors, oriented at a grazing angle of $8^{\circ}$, as an optical low pass filter. The reflectivity of the mirror pair was less than 0.05 for energies above $200 \mathrm{eV}$ resulting in the spectral region of $100-300 \mathrm{eV}$ being virtually free from order sorting problems. Light emerging from this optical low pass filter was coincident with the optic axis of the spectrometer as the mirrors were aligned parallel to each other. XUV spectra from a number of targets including Mylar ${ }^{\circledR}$ $\left(\mathrm{C}_{10} \mathrm{H}_{8} \mathrm{O}_{4}\right)$ and copper tapes, and samarium, lead, and gold rods were recorded.

To measure the duration of plasma emission, time resolved emission data were obtained with a Kentech ${ }^{\mathrm{TM}}$ streak camera. Dispersed spectra were not streaked due to the lack of toroidal coupling optics between source and spectrometer which resulted in insufficient flux. Instead a simple thin film of Mylar ${ }^{\circledR}$ was used for vuv filtering. The XUV window defined by the gold mirror pair and a 0.2- $\mu$ m-thick Mylar ${ }^{\circledR}$ filter has a peak transmission of $18 \%$ at approximately 145 $\mathrm{eV}$ and provides a FWHM bandpass of $85 \mathrm{eV}$.

Time integrated, predominantly first-order spectra of Mylar®, copper, and samarium obtained with the FFS operating in high resolution mode are shown in the $100-200 \mathrm{eV}$ energy range in Fig. 2. The spectra shown are uncorrected for the combined reflectivity of the gold mirror pair and grating. Calibration data on the spectral response of the phosphor coated face plate cum CCD detector ${ }^{31}$ was used to convert counts/pixel to photons $/ \mathrm{mm}^{2}$ in the focal plane of the spectrometer. The spectra represent an average of the accumulation of 1000 laser pulses on target, each with a mean energy of $15 \mathrm{~mJ}$ per pulse. The left hand side $y$ axis in Fig. 2 refers to copper and samarium spectra while the corresponding axis on the right hand side refers to the Mylar® spectrum. The transition from predominantly line emission to line free continuum emission as the target atomic number is increased is clear. At high resolution, samarium produces a smooth continuum whereas XUV emission from copper is more intense

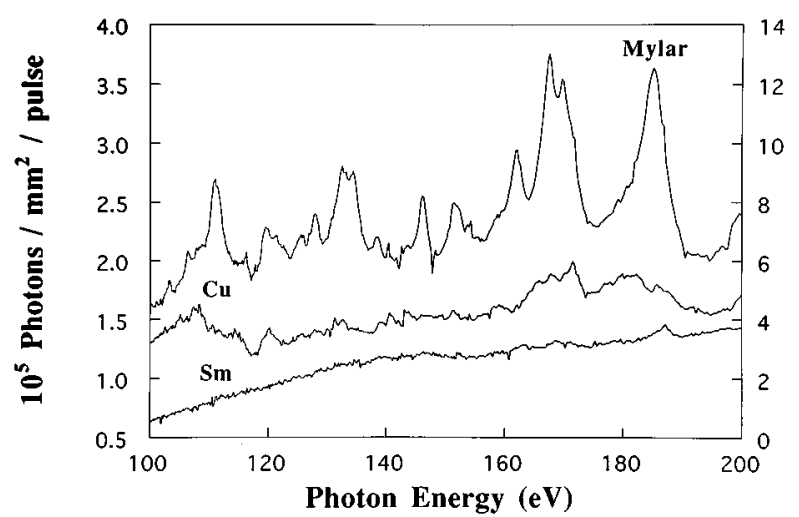

FIG. 2. Mylar®, Copper, and Samarium spectra obtained in high resolution mode (Slit width $=75 \mu \mathrm{m}$ ). The $y$-axis graduations on the left hand side refer to $\mathrm{Cu}$ and $\mathrm{Sm}$ while those on the right hand side refer to Mylar®.

but with increased line structure which reduces it's attractiveness for photoabsorption applications.

The single shot sensitivity of the source-spectrometer system was demonstrated by removing the entrance slit to allow increased flux to fall on the detector plane. A single shot emission spectrum from a lead plasma with an average of $2 \times 10^{6}$ photons per $\mathrm{mm}^{2} /$ pulse at $h \nu=200 \mathrm{eV}$ is shown in Fig. 3 . The system gain will be significantly increased in the future using toroidal coupling optics resulting in sufficient flux yields for potential applications requiring single-shot sensitivity at high spectral resolution such as dynamics of laser ablated plasma plumes used in pulsed deposition techniques. $^{32}$

The relative intensities of XUV continua produced by the high atomic number metals lead, gold, and samarium are shown uncorrected for grating/mirror response in Fig. 3. The spectra represent the mean value of the accumulation of 100 laser pulses on target with an average energy of $15 \mathrm{~mJ}$ per pulse. Lead produces the brightest continuum and it's low cost and ease of machining make it a strong candidate for an XUV, short pulse duration, continuum light source. In order to investigate the spectral reproducibility of the source, two consecutive lead spectra were accumulated over 100 laser shots each $\left(I_{1}\right.$ and $\left.I_{2}\right)$. The ratio $I_{1} / I_{2}$ was calculated and this procedure was repeated for a series of similarly recorded pairs of spectra. The ratios obtained lie within $\pm 5 \%$ of an expected value of 1 and serve to demonstrate the high degree

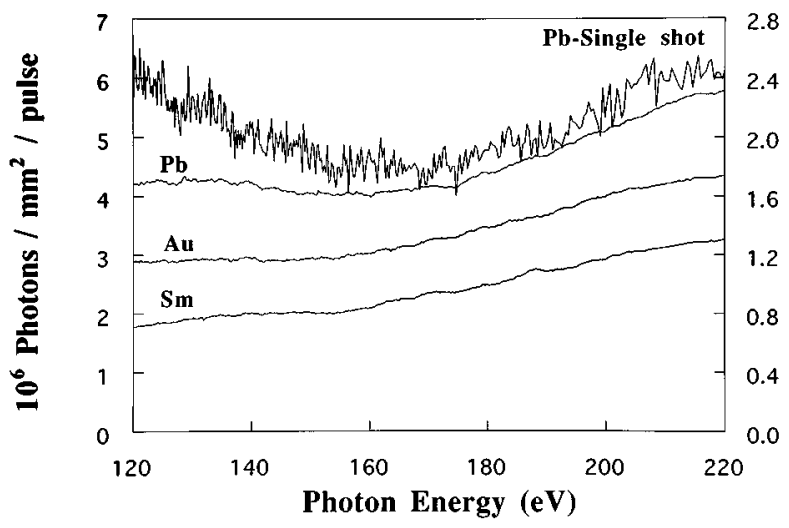

FIG. 3. Comparison of continuum emission spectra obtained from a number of high- $Z$ plasmas recorded with the flat field spectrometer in slitless mode. 


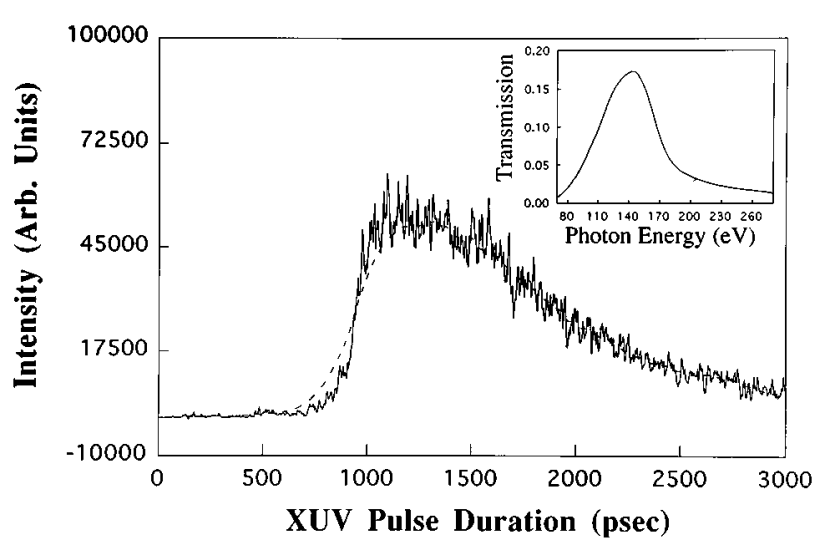

FIG. 4. Time history of XUV emission from a lead plasma. Inset: The spectral window as defined by the gold mirror pair and $0.2 \mu \mathrm{m}$ Mylar ${ }^{\circledR}$ filter.

of reproducibility of the spectral content of the source.

Figure 4 shows the XUV pulse duration of emission from a lead plasma. Photon energies detected lay in the spectral window defined by the gold mirror pair and a $0.2-\mu \mathrm{m}$ thick Mylar® transmission filter (see inset Fig. 4). The emission pulse rise time was rapid $(\sim 150 \mathrm{ps})$ limited by the streak camera resolution of $\sim 100$ ps with a long fall time resulting in a FWHM of $\sim 750$ ps. This duration is long in comparison with the result obtained by Davidson ${ }^{31}$ who measured pulse durations of $\sim 100$ ps at $30 \AA(413 \mathrm{eV})$ for a thulium target with an incident laser pulse carrying $50 \mathrm{~J}$ in 80 ps on to a $200 \mu \mathrm{m}$ diam spot, resulting in an on-target irradiance of $\sim 10^{15} \mathrm{~W} / \mathrm{cm}^{2}$. Two main factors are believed to contribute to this result. (i) The Mylar® filter provides excellent blocking in the VUV but it has a non-negligible transmission in the UV and visible regions of the spectrum which may provide a long "tail" superimposed on the XUV emission pulse; (ii) A $20 \mathrm{~ns}, 25 \mathrm{~mJ}$ amplified spontaneous emission (ASE) pulse from the $\mathrm{KrF}$ amplifier stage was transmitted to the target resulting in a dilute preplasma which was then pumped with the 7 ps pulse. Hence, we are dealing not with a simple laser-solid interaction. It is well established that the volume of the emitting plasmas in the XUV is increased significantly in the case of laser-preplasma interactions over laser-solid target interactions (see, e.g., Ref. 33). It is likely that the emission time increases correspondingly as the larger XUV emitting plasma volume will have a longer characteristic expansion and cooling timescale given by $\tau$ $=L / v \cong 500$ ps where $L \cong 50 \mu \mathrm{m}$ is the estimated axial extent of the cool preplasma and $L \cong 10^{7} \mathrm{~cm} / \mathrm{s}$ is a typical expansion velocity of the hot plasma. A clear observation of the increase in the x-ray emission time in the presence of an ASE generated preplasma has been shown by Kieffer and coworkers. ${ }^{14}$ Their experiments show an increase in $\mathrm{x}$-ray emission pulse width by a factor of five or so over a direct laser-target interaction. Experiments with a controllable degree of preplasma formation and XUV detection with ps time resolution will be required to settle this question.

In conclusion, we have shown that a picosecond tabletop laser may be used to generate line-free, XUV continuum radiation with a pulse duration of $<750 \mathrm{ps}$. In the near future, we will carry out comparable studies with an ASE-free picosecond laser driver with a view to obtaining shorter duration XUV emission and also to demonstrate the use of the light source in dual-laser plasma ${ }^{26}$ experiments.

This work was funded under the EU-Human Capital Mobility programme. The DCU Group acknowledges partial support from Forbairt (The Irish Science and Technology Agency).

${ }^{1}$ C. B. Darrow, C. Coverdale, M. D. Perry, W. B. Mori, C. Clayton, K. Marsh, and C. Joshi, Phys. Rev. Lett. 69, 442 (1992).

${ }^{2}$ J. D. Kmetec, C. L. Gordon III, J. J. Macklin, B. E. Lemoff, G. S. Brown, and S. E. Harris, Phys. Rev. Lett. 68, 1527 (1992).

${ }^{3}$ J. J. Macklin, J. D. Kmetec, and C. L. Gordon, III, Phys. Rev. Lett. 70, 766 (1993).

${ }^{4}$ H. Hamster, A. Sullivan, S. Gordon, W. White, and R. W. Falcone, Phys. Rev. Lett. 71, 2725 (1993).

${ }^{5}$ A. Modena, Z. Najmudin, A. E. Dangor, C. E. Clayton, K. A. Marsh, C. Joshi, J. Malka, C. B. Darrow, C. Danson, D. Neely, and F. N. Walsh, Nature (London) 377, 606 (1995).

${ }^{6}$ M. M. Murnane, H. C. Kapteyn, and R. W. Falcone, Phys. Rev. Lett. 62, 155 (1989).

${ }^{7}$ B. Soom, H. Chen, Y. Fisher, and D. D. Meyerhofer, J. Appl. Phys. 74, $5372(1993)$

${ }^{8}$ D. Umstadter, X. Liu, and J. Workman, Proc. SPIE 1860, 80 (1993).

${ }^{9}$ I. C. E. Turcu, I. N. Ross, and G. J. Tallents, Appl. Phys. Lett. 63, 3046 (1993).

${ }^{10}$ J. F. Pelletier, M. Chaker, Y. Beaudoin, C. Y. Côté, and J. C. Kieffer, Proc. SPIE 2041, 222 (1994).

${ }^{11}$ P. Audebert, J. P. Geindre, A. Rouse, F. Falliès, J. C. Gauthier, A. Mysyrowicz, G. Grillon, and A. Antonetti, J. Phys. B: At. Mol. Opt. Phys. 27, 3303 (1994).

${ }^{12}$ R. Shepherd, R. Booth, D. Price, M. Bowers, D. Swan, J. Bonlie, B. Young, J. Dunn, B. White, and R. Stewart, Rev. Sci. Instrum. 66, 719 (1995).

${ }^{13}$ G. T. Schappert, J. A. Cobble, R. D. Fulton, G. A. Kyrala, G. L. Olson, and A. J. Taylor, AIP Conf. Proc. 318, 97 (1994).

${ }^{14}$ J. C. Kieffer and M. Chaker, J. X-ray Sci. Technol. 4, 312 (1994).

${ }^{15}$ M. M. Murnane, H. C. Kapteyn, S. P. Gordon, and R. W. Falcone, Appl. Phys. B 58, 261 (1994).

${ }^{16}$ J. F. Pelletier, M. Chaker, and J. C. Kieffer, Opt. Lett. 21, 1040 (1996).

${ }^{17}$ J.-P. Mosnier, S. Bac, R. Barchewitz, E. T. Kennedy, M. Collins, and J. T. Costello, J. Electron Spectrosc. Relat. Phenom. 80, 295 (1996).

${ }^{18}$ P. K. Carroll, E. T. Kennedy, and G. O'Sullivan, Appl. Opt. 19, 1454 (1980).

${ }^{19}$ P. K. Carroll, E. T. Kennedy, and G. O’Sullivan, Opt. Lett. 2, 72 (1978).

${ }^{20}$ G. O'Sullivan, J. R. Roberts, W. R. Ott, J. M. Bridges, T. L. Pittman, and M. Ginter, Opt. Lett. 7, 31 (1982).

${ }^{21}$ Ch. Heckenkamp, U. Heinzmann, G. Schönhense, D. D. Burgess, A. P. Thorne, and J. E. G. Wheaton, J. Phys. D: Appl. Phys. 14, L203 (1981).

${ }^{22}$ P. Gohil, H. Kapoor, D. Ma, M. C. Pekerar, T. J. McIlrath, and M. L. Ginter, Appl. Opt. 24, 2024 (1985).

${ }^{23}$ M. L. Bortz and R. H. French, Appl. Phys. Lett. 55, 1955 (1989).

${ }^{24}$ G. D. Kubiak, D. A. Outka, C. M. Rohlfing, J. M. Zeigler, D. L. Windt, and W. K. Waskiewicz, J. Vac. Sci. Technol. B 8, 1643 (1990).

${ }^{25}$ K. Murakami, T. Ohyanagi, A. Miyashita, and O. Yoda, AIP Conf. Proc. 288, 375 (1994).

${ }^{26}$ J. T. Costello, J.-P. Mosnier, E. T. Kennedy, P. K. Carroll, and G. O'Sullivan, Phys. Scr. T34, 77 (1991).

${ }^{27}$ E. T. Kennedy, J. T. Costello, J.-P. Mosnier, A. A. Cafolla, M. Collins, L. Kiernan, U. Köble, M. H. Sayyad, and M. Shaw, Opt. Eng. (Bellingham) 33, 3984 (1994)

${ }^{28}$ S. J. Davidson, D. Neely, C. L. S. Lewis, and D. O'Neill, Rutherford Appleton Laboratory Report No. RAL-90-026, 13 (1990).

${ }^{29}$ I. C. E. Turcu, I. N. Ross, P. Trenda, C. W. Wharton, R. A. Meldrum, H. Daido, M. S. Schultz, P. Fluck, A. G. Michette, A. P. Juna, J. R. Maldonado, H. Shields, G. J. Tallents, L. Dwivedi, J. Krishnan, D. L. Stevens, T. J. Jenner, D. Batani, and H. Goodson, Proc. SPIE 2015, 243 (1994).

${ }^{30}$ T. Kita, T. Harada, N. Nakano, and H. Kuroda, Appl. Opt. 22, 512 (1983).

${ }^{31}$ A. G. MacPhee and C. L. S. Lewis, AiP Conf. Proc. 332, 441 (1994).

${ }^{32}$ T. Makimura, T. Sakuramoto, and K. Murakami, Jpn. J. Appl. Phys. 35, L735 (1996).

${ }^{33}$ J. Steingruber, S. Borgström, T. Starczewski, and U. Litzén, J. Phys. B: At. Mol. Opt. Phys. 29, L75 (1996). 